\title{
NA PONTA DO ALFINETE: UM ESTUDO SOBRE FRONTEIRA DE CORNÉLIO PENNA'
}

\author{
AT THE TIP OF THE PIN: \\ A STUDY ON CORNÉLIO PENNA'S FRONTEIRA
}

\author{
Josalba Fabiana dos Santos²
}

RESUMO: Comparamos três momentos paradigmáticos em Fronteira (1935), primeiro romance de Cornélio Penna (1896-1958). Maria Santa, a protagonista, e o narrador observam uma caixa de tampo de vidro contendo pequenos animais espetados por alfinetes. Esta caixa é uma metáfora da violência realizada pelos romeiros, que espetam Maria Santa também com alfinetes, e pelo narrador, que a estupra. Como os pequenos animais e Maria Santa são associados ao estranho e ao monstro, utilizamo-nos de Freud (1976), Nazário (1998), Cohen (2000) e Agamben (2010) para analisar o processo de desumanização sofrido pela protagonista e que facilitará a violência de que será vítima.

Palavras-chave: Cornélio Penna. Fronteira. Violência.

ABSTRACT: Three paradigmatic moments in Fronteira (1935), Cornelio Penna's (1896-1958) first novel, were compared. Maria Santa, the protagonist, and the narrator observe a glass-topped box containing small pins-stuck animals. This box is a metaphor for the violence performed by the pilgrims, who poke Maria Santa with pins, and by the narrator, who rapes her. As small animals and Maria Santa are associated with the stranger and the monster, Freud (1976), Nazario (1998), Cohen (2000) and Agamben (2010) were used to analyse the dehumanization process suffered by the protagonist and that will facilitate the violence of which she will be a victim.

Keywords: Cornélio Penna. Fronteira. Violence.

\section{Introduçằo}

Fronteira $(1935)^{3}$, nosso objeto de estudo, foi o primeiro romance publicado por Cornélio Penna, autor também de Dois romances de Nico Horta (1939), Repouso (1948) e A menina morta (1954).

\footnotetext{
${ }^{1}$ Artigo recebido em 14 de agosto de 2019 e aceito para publicação em 22 de novembro de 2019. 2 Doutora pela UFMG; professora associada III na Universidade Federal de Sergipe; membro do grupo de pesquisa Crimes, Pecados e monstruosidades (UFMG); josalba@ufs.br.

${ }^{3}$ Adaptado em 2008 para o cinema por Rafael Conde. 
Em uma pequena e decadente cidade do interior mineiro, em um sobrado igualmente decadente, em fins do século XIX, vive Maria Santa, sozinha, sem familiares ou amigos. O Santa parece ser uma alcunha atribuída como resultado de suas supostas habilidades espirituais. Tais habilidades atraem a visita repentina de tia Emiliana, que pretende administrar os peregrinos que acorrem ao sobrado e sobretudo capitalizar suas oferendas. Antes mesmo da velha parenta, chega o enigmático narrador-personagem, do qual pouco se sabe - nem mesmo seu nome nos é revelado. É por meio dele que temos acesso a um clima misterioso e lúgubre, a episódios dramáticos e mal-explicados.

Selecionamos três momentos da narrativa como foco de análise, sendo que todos envolvem alguma violência. O primeiro é quando somos apresentados a uma caixa repleta de animais espetados por alfinetes. 0 segundo é quando Maria Santa é quem será espetada por alfinetes pelos peregrinos. E o último é quando a mesma personagem será estuprada. No decorrer do nosso estudo, consideramos relevante também analisar o processo de rebaixamento ao qual Maria é submetida como facilitador das violências que sofre.

\section{Alfinetes no palheiro: os primeiros}

Logo nos primeiros capítulos de Fronteira, o narrador e Maria Santa observam:

[...] uma grande caixa oblonga, com tampa de vidro, emoldurada de cabiúna e peroba, num desenho forte e simples que formava um quadro de pesado e faustoso mau gosto. / Através dos vidros viam-se bichos e reflexos fulvos, uns, outros rubros como brasas, com carapaças cinzeladas em detalhes infinitamente pacientes. Outros ainda, verdes e trabalhados como joias antigas, pareciam dormitar ali dentro, tal a gentil e ingênua naturalidade com a qual tinham sido dispostos. (PENNA, 1958, p. 53)

A caixa, também chamada de quadro no romance, foi feita pela Marquesa de Pantanal, após a morte do marido. Mais tarde deu-o à avó de Maria Santa. Portanto, é uma espécie de herança passada de uma mulher a outra. Estranha herança, pois o que temos são animais mortos postos em exibição. Coleções dessa natureza foram muito comuns no Brasil do século 
XIX e eram feitas sobretudo por naturalistas estrangeiros homens. Em nome da ciência, animais eram caçados e mortos, classificados e fixados em vitrines para organização, transporte e exposição. Aparentemente, a coleção da Marquesa não tem nenhum intuito científico. Luiz Costa Lima (1976), sem se alongar em detalhes, destaca a caixa como uma metáfora da violência que subjaz a narrativa. Como veremos neste trabalho, sua presença não é gratuita, pois sintetiza e antecipa a violência que subjuga Maria Santa, mimetizando inclusive seu método: espetar alfinetes.

Maria Santa, sua avó, a Marquesa e todas as mulheres estavam submetidas aos desmandos da sociedade patriarcal e, infelizmente, muitas vezes reproduziram esses desmandos. O narrador imagina um pouco da existência da Marquesa após a viuvez:

[...] revivi toda a angústia daquela mão distraída [...]. / Certamente aquele quadro tinha sido o companheiro e recreio da Marquesa, em seus longos anos vazios que a fizeram compreender o vazio do além. Nas intermináveis horas de angústia solitária, era ele que decerto a ajudava a fugir de sua tentação sombria e silenciosa, que dela se aproximava de súbito, como o golpe de asa de uma ave noturna. (PENNA, 1958, p. 54, grifo nosso)

Ao mesmo tempo em que se compadece de uma vida cheia de angústias e solidão, o narrador não deixa de lançar o seu olhar de homem integrado ao patriarcalismo ao mencionar a "tentação sombria e silenciosa" que rondaria aquela senhora - e, por extensão, a todas as mulheres. $O$ uso da palavra tentação, nesse contexto, nos conduz a pensar na sexualidade a ser reprimida. Uma vez viúva - sem marido, portanto - a Marquesa estaria fragilizada por seus próprios desejos, o que era inaceitável para uma mulher naquele momento histórico. Interessante pontuar que o local ao qual o seu título nobiliárquico se refere ressaltaria a vitalidade e o erotismo que necessitavam ser sufocados, já que o Pantanal, como todos sabemos, é um dos biomas mais ricos no que tange à diversidade da flora e fauna do Brasil. De maneira que, ao ter a própria vitalidade negada, a Marquesa passa a negar a vitalidade dos animais que captura, alfinetando-os e exibindo-os como troféus. No rigor, a Marquesa reproduz com os animais o que fazem com ela. A senhora espelha e reflete o próprio mundo no qual vive. O tampo de vidro da caixa naturalmente facilita esse processo. Por isso a Marquesa presenteia 
a avó de Maria, que por sua vez deixará o violento legado à neta. Dessa forma a lógica do aprisionamento das mulheres é mostrada pela caixa-mostruário. Os insetos e pequenos animais são amostras que mimetizam a condição feminina no sistema patriarcal.

Para prosseguirmos na investigação de palavras do mesmo campo semântico (caixa-mostruário, mostrada e amostra), destacamos que o narrador se refere a um dos insetos ali presos como "monstrengo" (PENNA, 1958, p. 54). O monstro "situa-se como uma advertência contra a exploração de seu incerto território" (COHEN, 2000, p. 41), daí seu aspecto abjeto. Estendendo essa impressão causada pelo inseto à caixa, vemos que ela se torna uma espécie de aviso, de lembrete ou de ameaça do que poderia acontecer com aquelas que tentassem saltar as estreitas fronteiras (não por acaso o título do romance) do patriarcalismo.

Ao repetir palavras como tentação e tentativa, ressaltamos a sua proximidade semântica, como fizemos com mostruário, mostrar, amostra e monstro. Reproduzimos assim um recurso utilizado por Cornélio Penna em seu romance: a repetição. Mais do que repetir palavras, ele repete situações. Tais repetições reiteram e ressaltam a importância da cena da caixa que pode passar desapercebida para uma leitora ou leitor desavisados, apesar de ser a peça central de um dos capítulos. Aliás, também esse é um recurso narrativo em Cornélio Penna: apresentar situações, personagens e/ou objetos como se fossem detalhes destituídos de valor, quando são peças fundamentais de um quebra-cabeça bastante complexo, são pistas que nos ajudarão a compreender melhor o que virá.

Retomando o capítulo dedicado à caixa, observamos o narrador destacando seu aspecto lúgubre:

\begin{abstract}
Reparei com atenção e distingui a um canto, como se estivesse ali de tocaia, pregado com alfinetes no fundo formado de orelhas de pau gigantescas, coladas umas às outras, uma espécie de enorme besouro, aranha ou escorpião de tamanho desusado, pois lembrava a todos três, e tirava de cada um, com assustadora simplicidade, os seus aspectos mais inquietantes. (PENNA, 1958, p. 54)
\end{abstract}

Esse pequeno animal indefinido, fora da normalidade ou do conhecimento (ao menos daquele que o observa), apesar de morto, é descrito como se estivesse de tocaia. $\mathrm{O}$ que nos remete de imediato a vigília constante 
à qual estavam submetidas a Marquesa e as demais mulheres. Qualquer coisa que fizessem poderia ser notado e a punição seria imediata, afinal, o sistema patriarcal e seus agentes estavam sempre à espreita. No entanto, outro aspecto nos atrai a atenção: o uso da palavra inquietante. Essa é a palavra utilizada no título de uma das traduções para o português do clássico ensaio "O 'estranho", de Freud, escrito em 1919. Em um primeiro momento, pensamos que o estranhamento vem de algo incomum, inusitado. É assim que a caixa é vista pelo narrador: como inesperada e inquietante. No entanto, segundo Freud (1976, p. 277), "o estranho é aquela categoria do assustador que remete ao que é conhecido, de velho, e há muito familiar" - familiar no sentido de ser algo com o que já teríamos tido contato, mas, por algum motivo, solaparíamos. E é talvez por isso que o título do artigo freudiano traga a palavra entre aspas, porque o estranho não é estranho, tratar-se-ia de uma ironia.

Se consideramos a caixa como metáfora da violência, vemos que apenas antecipa e resume o que virá adiante: o sistema patriarcal opressor. Mas o que virá adiante para nós já é dominado há muito pelo narrador. Logo, a caixa que the parece estranha é, na verdade, sua velha conhecida. Não enquanto caixa, mas como realização de um sistema complexo de violências do qual ele, inclusive, é parte integrante. O que nos faz pensar que o narrador estranha a caixa porque não quer reconhecê-la, ou melhor, porque não quer se reconhecer naquilo que vê e pratica. Nesse sentido, ele resiste ao espelhamento.

\section{Tentando se (des)encaixar}

Maria Santa tenta se adequar às exigências do patriarcalismo, todavia, ela também tenta exercer sua sexualidade. Como era de se esperar, essas forças antagônicas criam uma série de tensões em torno dela. Naturalmente sua fama de milagreira não a torna santa, pois, ela teria ferido de maneira profunda a estrutura do sistema no qual está inserida, pois praticou sexo fora do casamento e por isso foi e prossegue sendo punida. Maria Santa perdeu o noivo, assassinado, em mais um dos "crimes da sua família brutal" (PENNA, 1958, p. 62). Aparentemente foi o defloramento que causou o crime. $O$ episódio rendeu a ela uma espécie de prisão domiciliar velada. Em nenhuma hipótese Maria deixa a casa e seus contatos com outras pessoas são raros. Um forte sentimento de culpa parece envolvê-la. Em um 
ambiente religioso, repressor e punitivo, a transgressora vive sob o peso de remorsos. "Com o delito se constroem consciências culpadas", comenta Josefina Ludmer (2002, p. 11). Não à toa, Maria afirmará ao narrador com veemência: "Não sou digna! mas, não sou digna! agora é tarde! depois do que se passou é tarde! é tarde!" (PENNA, 1958, p. 57). Do que ela não seria digna? Provavelmente dos milagres que realiza. O que teria acontecido? A descoberta pela família da relação sexual com o noivo é uma resposta plausível no contexto da narrativa (fins do século XIX).

A repressão não impede que Maria Santa tenha ciência do próprio corpo. Ela tem desejos sexuais e tenta realizá-los, continuando assim a contrariar a moral do patriarcado mesmo sob punições (o assassinato do noivo e a vida reclusa a que foi e é submetida). O pequeno espaço que lhe é reservado, a casa, e as raras visitas que recebe, não a impedem de procurar a concretização de seus desejos.

A casa da/de família é o espaço da mulher dentro da estrutura patriarcal. No rigor do termo, a casa é seu único espaço, seja como confinamento, seja como proteção. Ali a mulher está detida ou retida. Ali ela está protegida. No fundo, se retida e/ou se protegida tanto faz, tratam-se de duas faces da mesma moeda, já que a casa-prisão-proteção serve como local de controle do corpo feminino. A mulher está aprisionada para que não desfrute, nem se dê ao desfrute; assim como ela tem seu corpo protegido. Em suma, quem aprisiona e quem está realmente protegida é a ordem patriarcal.

O mais distante da casa que Maria Santa transita é pelo jardim da propriedade, onde ela tenta satisfazer seus desejos. Durante um passeio noturno, o narrador relata:

Senti [...] uma mão trêmula agarrar-me o braço, e unhas, em garra enterraram-se na minha carne. Um bafo quente chegou-me até à boca, adocicado e morno, e senti que todo o meu corpo se encostava a outro corpo, em um êxtase doloroso e longo, inacabado e insatisfeito... (PENNA, 1958, p. 65)

O narrador não nomeia Maria Santa. Ela é apenas uma mão, unhas e tem um bafo quente. É assim fragmentada, pulverizada em metonímias. De certa maneira, a protagonista é apartada do próprio corpo. Processo interessante à estrutura patriarcal, pois ao afastar a mulher do seu corpo, 
abre-se um espaço para outras posses. Sendo que essas outras posses costumam ser exercidas pelo pai, a princípio e por princípio, sem toques, e pelo marido, que a exercerá como melhor lhe aprouver. A jovem não deve ser maculada por ninguém antes do casamento para que seu valor seja mantido. No entanto, Maria não tem mais pai nem nunca teve marido, o que não a torna de forma alguma proprietária do próprio corpo. A sociedade em seu entorno é suficiente e eficiente em controlá-la.

Retomando a citação acima, é como se não fosse possível (ou desejável) ao narrador relacionar a moça que se afastara dele no momento anterior com a imagem voluptuosa e sensual que retornara. E assim ele continua a sua descrição do episódio:

Quando voltei a mim, procurei afastar com violência o monstro que viera das trevas, mas estava só de novo, e voltei para casa, sem explicar o que me sucedera, e, já no meu quarto, lavei a boca, o rosto e as mãos, como o fazem os criminosos, para apagar os vestígios de seu crime... (PENNA, 1958, p. 65)

É inegável a visão moralista do narrador. O ato sexual é comparado a um crime do qual ele se sente culpado. Também nele ecoam as palavras de Ludmer: "Com o delito se constroem consciências culpadas" (2002, p. 11). E o crime que supostamente teria sido cometido deve ter seus vestígios apagados com o máximo cuidado, a sujeira deve ser apartada. Logo, o sexo é associado à impureza e não ao prazer pelo narrador nesse momento.

E se ele, a suposta vítima atacada, sente-se culpado, isso só reforça a metáfora de Maria Santa como sendo um monstro. É esse monstro que o narrador disse ter afastado com violência. Cohen (2000) afirma que a mulher, quando ultrapassa as fronteiras do seu papel de gênero, arrisca tornar-se um monstro, portanto, ela deixa de ser controlável pela sociedade. Se voltamos à citação que privilegiava mão, unhas em garra e a boca (não mencionada de forma direta, mas implícita no bafo quente) percebemos a pertinência de uma observação tecida por Luiz Nazário:

A monstruosidade começa verdadeiramente a imporse a partir dos olhos [suprimidos e desnecessários no caso de Maria, pois está escuro], da boca e das mãos. São essas as partes do corpo que mais exteriorizam o desejo e, quando pervertidas, na máscara monstruosa, externam o desejo perverso, desencadeado 
fisiologicamente e sem controle [...]. (NAZÁRIO, 1998, p. 13)

O monstro quer agarrar e devorar suas presas. Maria Santa não pode ser uma mulher com desejos sexuais ou desejável, segundo o narrador, sequer é uma mulher. Ela é um monstro que viera das trevas para atacá-lo. Ou será o contrário? Maria é monstro por que é uma mulher, por que tem, demonstra e tenta realizar seus desejos? Em outras palavras, o que faz dela um monstro aos olhos do narrador é o fato dela ser uma mulher que não reprime sua sexualidade. Eis a perversidade de Maria: ter desejos e externálos.

Ainda para Luiz Nazário (p. 117, 1998): “à palavra 'monstro' associaram-se, primariamente, traços típicos do macho guerreiro - violência, ferocidade, intolerância, voracidade, arrogância". Enquanto, "a feminilidade construiu-se em oposição aos valores da monstruosidade". Por isso, segundo o mesmo autor: "as mulheres que divergem, mental ou biologicamente, do eterno feminino, tendem a ser monstrificadas".

É o mesmo que afirma Jeffrey Jerome Cohen (2000) em outras palavras: toda mulher que transgride o espaço que a sociedade lhe reservou se arrisca a virar um monstro. Esse espaço é extremamente pequeno no Brasil de fins do século XIX. No romance de Cornélio Penna, as estreitas fronteiras que delimitavam e aprisionavam Maria Santa foram ultrapassadas. A suposta indisciplina dela contribui para a desorganização do sistema vigente. Logo, ela deve ser detida. Ainda para Cohen:

Essas fronteiras são colocadas, primariamente, para controlar o tráfico de mulheres ou, mais geralmente, para estabelecer vínculos estritamente homossociais os laços entre homens que fazem com que a sociedade patriarcal continue sendo funcional. (Cohen, 2000, p. 43)

É o controle do tráfico de mulheres que permite ao patriarcado a produção e a manutenção dos seus valores morais e riquezas materiais. Os vínculos homossociais são estabelecidos na articulação de casamentos endógenos - aqueles realizados dentro das mesmas famílias -, mas não só. No Brasil do século XIX, há endogenia sobretudo social, isto é, casamentos realizados dentro de um mesmo círculo, não permitindo que as fortunas se dispersassem. De qualquer maneira, é preciso destacar que na mesma família 
ou fora dela não há diferença significativa, o importante é que era o patriarca ou um de seus representantes (irmão, filho, tio e até mesmo esposa) quem traficava as mulheres. Era o patriarcado quem decidia sobre os corpos femininos. Às mulheres cabia apenas a aceitação e a resignação diante do casamento que thes fosse imposto. As "alternativas", igualmente decididas pelo patriarcado, eram o convento, a solteirice (a famosa tia) ou o prostíbulo. Ainda que o próprio patriarcalismo tivesse um lugar funcional para as solteiras descartadas do casamento (cuidar da vida doméstica - das crianças e da cozinha) e para as prostitutas (desfrutadas pelos homens do sistema), obviamente não era essa a situação idealizada, tampouco valorizada.

O fato de Maria Santa não ter um pai (nem mãe ou irmãos) no presente da narrativa está muito longe de implicar em ser livre, como já afirmamos. Sua família, os da sua casa, morreram ou desapareceram, mas o controle social que garante a manutenção do patriarcalismo permanece intacto. Vigiar o corpo de Maria Santa não interessa apenas à sua família, interessa a toda a comunidade que a envolve e condiciona.

\section{Cada vez mais desencaixada}

Maria Santa não tinha um corpo virgem para entregar ao casamento. Portanto, ela feriu a ordem patriarcal que a negaceava e negociava para sua própria manutenção e continuidade. Ao ultrapassar a fronteira que a circunscrevia em uma condição muito específica (a da castidade), Maria passa a ser vista como um monstro, como uma ameaça, e é como ameaça que a sua contenção e inclusive o seu extermínio se justificam. Afinal, "O monstro é transgressivo, demasiadamente sexual, perversamente erótico, um fora-da-lei: o monstro e tudo o que ele corporifica devem ser exilados ou destruídos" (COHEN, 2000, p. 48). Mas, enquanto ele existe, "o Monstro devasta" (NAZÁRIO, 1998, p. 16). A devastação causada por Maria pode ser percebida no esfacelamento familiar: todos morreram ou se foram, ela está só. Tal devastação deve ser detida, por isso Maria deve ser contida e rebaixada, seu valor deve ser diminuído para que compreenda que seu corpo não lhe pertence e como advertência e exemplo às demais mulheres. Todas elas devem entender a quem pertencem.

Cohen afirma ainda que: "O corpo monstruoso é pura cultura" (2000, p. 27), para nós, isso significa dizer que ele é produzido dentro da mesma comunidade que o teme, não vem de fora, como muitas vezes 
tendemos a pensar. Após explicar a etimologia da palavra monstro como sendo aquele que revela e adverte, Cohen acrescenta:

[...] o monstro significa algo diferente dele: é sempre um deslocamento; ele habita, sempre, o intervalo entre o momento da convulsão que o criou e o momento no qual ele é recebido - para nascer outra vez. (COHEN, 2000, p. 27)

Maria Santa como monstro não é Maria Santa, não é reconhecida como ela deveria ser no estreito universo no qual vive: por isso o narrador só vê suas mãos em garra, desvincula dela sua humanidade e assim estabelece um distanciamento. "Não há monstros entre iguais", afirma Nazário (1998, p. 29), porque ele é uma: "Forma extrema da alteridade". O monstro precisa ser diferente de nós para que o pensemos como tal. E é também por esse motivo que o lugar ocupado pela monstruosidade é a fronteira - outra interpretação possível para o título do romance de Cornélio Penna. O monstro é o estranho à comunidade, mas esse estranho, de alguma maneira, é familiar. Naturalmente, como psicanalista, Freud não estava pensando em agrupamentos, mas em indivíduos para quem:

[...] esse estranho não é nada novo ou alheio, porém algo que é familiar e há muito estabelecido na mente, e que somente se alienou desta através do processo da repressão. Essa referência ao fator da repressão permite-nos, ademais, compreender a definição de Schelling do estranho como algo que deveria ter permanecido oculto, mas veio à luz. (FREUD, 1976, p. 301)

Maria Santa, da forma como é apresentada pelo narrador, é exemplar de tal ambivalência do estranho e, por extensão, do monstro, afinal o monstro é um tipo de estranho. Ter praticado sexo fora do casamento a torna uma excrescência à ordem patriarcal, todavia, se ela não fosse parte desta ordem - familiar a ela, portanto - sua atitude não seria um problema. Maria deveria ter permanecido silenciada no sobrado, mas isso não é possível o tempo todo. É porque é um dos membros do patriarcado que ela se torna estranha e monstruosa ao mesmo tempo. Esse sistema adestra suas mulheres e, quando falha, cria seus próprios monstros. 


\section{0 corpo santo e os novos alfinetes}

O corpo de Maria Santa não é só monstruoso, é santificado, mas isso está longe de ser uma vantagem, pois o corpo santo tampouco the pertence. Também nessa condição ela será controlada, vigiada e manipulada, inclusive literalmente. Durante a semana da Páscoa, Maria entra numa espécie de transe místico. Nesse momento o sobrado é assaltado por romeiros em busca do suposto milagre que ela realizará. Há muito se aguardava tal acontecimento. Tia Emiliana foi a principal responsável pela expectativa. O corpo de Maria é protegido apenas por duas imagens de santos e pela parenta oportunista, administradora sobretudo das oferendas deixadas, como dissemos anteriormente. Vejamos a descrição das visitas:

[...] depois do estalido seco das portas do aposento de Maria Santa, que se escancaravam, toda casa se animou, e o rumor pesado dos passos dos visitantes que agora entravam no quarto, as suas exclamações abafadas, os prantos que rompiam, irresistíveis, em altos soluços, ao verem que Maria Santa, muito pálida, de lábios cerrados, e a boca levemente azulada, não dava o menor sinal de dor, quando espetavam alfinetes em seus braços nus, colocados ao longo de seu corpo imóvel e estendido. E as orações, as súplicas de melhor vida, os pedidos de cura, feitos entre gemidos e suspiros, formavam uma estranha música [...]. (PENNA, 1958, p. 134)

Aparentemente é a ausência de qualquer manifestação de dor por parte de Maria o principal indício de que ali se realiza um milagre. É essa ausência que cria um verdadeiro fascínio em torno de sua imagem. Por isso é preciso continuar a espetá-la com alfinetes, porque essa é a maior prova do que estaria se processando naquele corpo. Algumas páginas adiante o martírio (senão para ela que está inconsciente, ao menos para nós que lemos) prossegue:

Os visitantes, que nos rodeavam, indiferentes às nossas preocupações, rezavam uns, ajoelhados, e de olhos fixos no rosto de Maria, enquanto outros, dela se aproximando, espetavam novos alfinetes em seus braços, furtivamente, com fria curiosidade, com o pretexto de se tornarem eles, depois, preciosas relíquias, que serviriam de socorro e alívio para muitos males. (PENNA, 1958, p. 139) 
Os alfinetes são espetados por dois motivos: porque tal gesto reitera a ausência de manifestação de dor, como vimos, e para se tornarem relíquias. Ambos confluem para a comprovação do milagre. Assim sendo, os alfinetes estenderiam as qualidades milagrosas de Maria Santa aos ausentes daquele ritual e/ou para outros momentos e lugares.

Esses os usos práticos e imediatos dos alfinetes espetados. Mas, para nós, esses pequenos objetos dizem mais, pois assinalam uma continuidade com a caixa mencionada anteriormente. Maria Santa é espetada como foram espetados os pequenos animais na caixa da Marquesa de Pantanal. E a exposição e acesso do seu corpo aos peregrinos não se limita a questões espirituais, afinal, como temos insistido, tia Emiliana agencia as visitas para satisfação de seus próprios interesses. Esse agenciamento toma tons de roubo, o que se esclarece quando é registrado, próximo ao final da narrativa, a partida da senhora levando as oferendas feitas pelos romeiros e também por uma cena em particular, quando um dos visitantes se comporta "como se" houvesse roubado Maria, fato que não pode ser analisado como mera comparação. Parece-nos que a comparação está a serviço de mais uma tentativa de naturalização do aviltamento do corpo da mulher, vejamos:

[...] o último visitante, depois de olhar-nos de soslaio, e tendo espetado, furtivamente, um alfinete no braço de minha amiga, se retirou como um ladrão, esbarrando nos móveis e não sabia onde esconder as mãos. (PENNA, 1958, p. 141)

A tentativa do romeiro de não mostrar as mãos, instrumentos do roubo e provável esconderijo do alfinete indica a consciência da sua vilania e o rebaixamento imposto a Maria. Agamben afirma algo bastante interessante para entendermos melhor a condição à qual ela fora reduzida:

Os gregos não possuíam um termo único para exprimir o que nós queremos dizer com a palavra vida. Serviamse de dois termos, semântica e morfologicamente distintos, ainda que reportáveis a um étimo comum: zoé, que exprimia o simples fato de viver comum a todos os seres vivos (animais, homens ou deuses) e bíos, que indicava a forma ou maneira de viver própria de um indivíduo ou de um grupo. (AGAMBEN, 2010, p. 9 , grifo do autor) 
Essa forma de viver própria de um indivíduo ou de um grupo é a vida do cidadão grego, um grupo, como sabemos, bastante restrito que excluía, entre outros, escravos e mulheres. Se transpusermos essa divisão para Fronteira, observamos que Maria Santa deixou de ter uma vida bíos (ao menos no nível das aparências) e passou a ter uma vida zoé. Ao ter a perda da sua virgindade tornada pública pelo assassinato do seu noivo, ela perdeu o valor de filha de uma família tradicional e foi tornada uma mulher qualquer. A realização sexual antes do casamento retirou de Maria o frágil elo que a mantinha do lado bíos da vida e a atirou ao seu lado "natural": zoé. É a mudança de condição, mais do que os milagres supostamente realizados, que autoriza os romeiros a espetarem seus braços. Se lembrarmos mais uma vez da caixa da Marquesa, Maria é espetada como um animal. Por outro lado, se pensarmos no lugar que ela (des)ocupa na vigilante estrutura patriarcal (sempre de tocaia a zelar pelos seus interesses), Maria Santa é espetada como uma mulher.

\title{
Do culto ao estupro
}

Após agenciar Maria como santa, tia Emiliana irá agenciá-la como objeto sexual, ainda que de forma sutil e indireta. Dessa vez a senhora entregará ao narrador a guarda do seu corpo - lembrando que a moça continua em transe, portanto inconsciente. Ordena a tia ao narrador:

\begin{abstract}
- Você velará Maria esta noite - disse-me, com suave autoridade, e fez cair, uma após outra, grandes contas de seu rosário - porque me sinto extraordinariamente cansada. / Estou exausta e com a cabeça perdida, pois há tantas noites não durmo, não descanso um só momento. Assim, você ficará só aqui, durante toda a noite, com o corpo da nossa Santa. / Parou mais alguns instantes, como se procurasse mais alguma coisa que me devesse dizer, e que, repentinamente, lhe tivesse fugido da memória. / Finalmente, prosseguiu com a sua voz sussurrante, doce e quente: - Ninguém virá perturbar o sossego sagrado deste quarto, nem você permitirá que o façam. (PENNA, 1958, p. 140)
\end{abstract}

Após ter colhido os frutos proporcionados pela sobrinha, tia Emiliana afrouxa sua guarda. Imediatamente o narrador reflete:

Desde que ouvi essas palavras, e senti nelas uma secreta intenção, não tive mais ânimo de sair de perto 
de Maria Santa, e ali fiquei até o último visitante, depois de olhar-nos de soslaio, e tendo espetado, furtivamente, um alfinete no braço de minha amiga, se retirou como um ladrão, esbarrando nos móveis e não sabia onde esconder as mãos. (PENNA, 1958, p. 141, grifo nosso)

Se em momento anterior aproximamos esse episódio ao roubo praticado por tia Emiliana, agora ampliamos a citação para destacar novo vínculo: desta vez com o narrador. Esse olhar de soslaio trocado entre quem conta a história e o romeiro é mais uma pista que antecipa a última violência praticada contra Maria Santa, o estupro. É um olhar cúmplice trocado entre dois homens que, resguardadas as devidas proporções, abusam de uma mulher que não pode defender o próprio corpo.

Sozinho com a moça, após observá-la por longo tempo em seu transe, o narrador termina por despir a túnica que a cobria.

Diante do corpo sem consciência de Maria Santa, fiquei imóvel durante minutos eternos, antes de estender as mãos e tocar com elas a prova real do que se passava em mim, e pude, afinal percorrer, agora já sem medo, os seus seios fortes, extraordinariamente fortes na linha alongada do perfil do seu corpo estendido, todo iluminado por uma luz unida, mágica e mole, que fazia transparecer, como um trabalho de marfim antigo, a caveira mal oculta pela carne lívida e translúcida. (PENNA, 1958, p. 145)

Assim inicia o estupro e quase um ato de necrofilia, pois Maria está prostrada como um cadáver. 0 estado em que ela se encontra e a túnica que a envolvia nos permitem tal afirmativa. E o narrador prossegue na sua narração sinistra:

Não me parecia cometer um crime moral, ao desvendar vagarosamente, um a um, os melancólicos segredos daquele corpo que todo ele se me oferecia e se recusava, ao mesmo tempo, em sua longínqua imobilidade. / Era uma caridade incomensurável que ele praticava, inconsciente, mas, por isso mesmo, mais valiosa e quase divina pela sua inocência puríssima, sobre-humana. (PENNA, 1958, p. 146)

Como é comum há vários violadores, o narrador não se reconhece como um criminoso (apenas lembra essa possibilidade para refutá-la). A culpa e a sensação de pecado que pareciam dominá-lo quando a iniciativa do sexo 
partia de Maria, desaparecem. E mesmo reconhecendo a possibilidade de uma recusa por parte da vítima, como muitos estupradores, ele prefere acreditar que o corpo inerte não só lhe está disponível, mas que se oferece, oferece-se a ele. Portanto, o narrador estaria autorizado a desfrutá-lo autorizado por um equívoco, é evidente. Ou silenciosamente autorizado. Afinal, o corpo de Maria, desvalorizado pela perda da virgindade, está, por princípio - princípio patriarcal, claro - acessível para ele e para outros, menos a ela própria.

O narrador-personagem que repudiara Maria Santa quando ela lhe manifestara seus desejos, denominando-a inclusive de monstro, faz sexo nela - e não com ela, é preciso que se destaque. O corpo de Maria não tem nenhuma reação diante da investida do narrador, ele mesmo reconhece sua (dela) inconsciência nas duas citações apresentadas acima. Todavia, essa inconsciência não o impede de satisfazer seus desejos - agora dele e somente dele. Essa cena, do estupro, mostra de forma irrefutável o lugar restrito reservado à mulher no patriarcado. O que ela quer não importa, não é considerado, aliás, é considerado como monstruoso, crime, pecado e sujeira. Maria teria investido sobre o narrador que caminhava totalmente consciente pelo jardim do sobrado. Investida que ele acolhera, apesar da repulsa e da culpa. O mesmo arrependimento que o levou a lavar as mãos como se fosse um criminoso. Mas não parece a ele estar cometendo nenhum "crime moral" nem de outra natureza quando penetra um corpo imóvel e inconsciente.

\section{Conclusằo}

Alfinetes, se pensados de forma tradicional, especialmente quando estamos diante de uma narrativa que se desenvolve no século XIX, remetem à costura e, por extensão, ao feminino, mas, como vimos, os de Fronteira têm outra finalidade. Os alfinetes da caixa com tampo de vidro são metáforas da violência que subjaz o sistema patriarcal e que se evidencia quando os romeiros espetam esses mesmos objetos em Maria Santa. Tal situação por sua vez também pode ser vista como metafórica, já que antecipa uma nova e radical violência: o estupro. Os romeiros espetam alfinetes sem qualquer preocupação com o mal que causam a Maria. Ela foi disponibilizada pela tia em particular e pelo patriarcalismo para ser o que desejarem que seja: objeto de veneração e culto (santidade) e objeto sexual, seja no estupro simbólico feito pelos peregrinos, seja no real feito pelo narrador. 
A violência contra a mulher é naturalizada, por isso ela é pode ser aniquilada. Os pequenos animais espetados por alfinetes na caixa da Marquesa metaforizam o estupro simbólico e real sofrido e nos mostram que mais do que comparada a um deles, Maria é estuprada porque é uma mulher. Em outras palavras, nesse contexto da narrativa jamais estaria um homem.

\section{Referências}

AGAMBEN, G. Homo Sacer: o poder soberano e a vida nua I. Trad. Henrique Burigo. 2. ed. Belo Horizonte: Ed. UFMG, 2010.

COHEN, J. J. A cultura dos monstros: sete teses. In: SILVA, Tomaz Tadeu da (org.). Pedagogia dos monstros: os prazeres e os perigos da confusão de fronteiras. Belo Horizonte: Autêntica, 2000. p. 23-60.

COSTA LIMA, L. A perversão do trapezista: o romance em Cornélio Penna. Rio de Janeiro: Imago, 1976.

FREUD, S. O 'estranho'. In: Edição Standard Brasileira das obras psicológicas completas de Sigmund Freud. Trad. Jayme Salomão. Rio de janeiro: Imago, 1976. v. XVII. p. 275-314.

LUDMER, J. $\mathrm{O}$ corpo do delito: um manual. Trad. Maria Antonieta Pereira. Belo Horizonte: 2002.

NAZÁRIO, L. Da natureza dos monstros. São Paulo: Arte \& Ciência, 1998.

PENNA, C. F. In: Romances completos. Rio de Janeiro: José Aguilar, 1958. 